\title{
Impaired mucosal defense to acute colonic injury in mice lacking cyclooxygenase-1 or cyclooxygenase-2
}

\author{
Olivier Morteau, ${ }^{1}$ Scott G. Morham, ${ }^{2}$ Rance Sellon, ${ }^{3}$ Levinus A. Dieleman, ${ }^{1}$ \\ Robert Langenbach, ${ }^{4}$ Oliver Smithies, ${ }^{2}$ and R. Balfour Sartor ${ }^{1}$ \\ ${ }^{1}$ Department of Medicine, and \\ ${ }^{2}$ Department of Pathology, University of North Carolina-Chapel Hill, Chapel Hill, North Carolina 27599, USA \\ ${ }^{3}$ Department of Medicine, School of Veterinary Medicine, North Carolina State University, Raleigh, North Carolina 27606, USA \\ ${ }^{4}$ National Institute of Environmental Health Sciences, Research Triangle Park, North Carolina 27709, USA
}

Address correspondence to: R. Balfour Sartor, Division of Digestive Diseases, Campus Box 7080, Room 030, Glaxo Building, University of North Carolina, Chapel Hill, North Carolina 27599, USA. Phone: (919) 966-0149; Fax: (919) 966-7468;

E-mail: rbs@med.unc.edu.

Olivier Morteau's current address is: Division of Pulmonary Medicine, Children's Hospital, Harvard University, Boston, Massachusetts 02115, USA.

Scott G. Morham's current address is: Myriad Genetics Inc., Salt Lake City, Utah 84105, USA.

Rance Sellon's current address is: Department of Veterinary Clinical Services, Washington State University, Pullman,

Washington 99164, USA.

Received for publication March 24, 1999, and accepted in revised form January 4, 2000.

To investigate roles in intestinal inflammation for the 2 cyclooxygenase (COX) isoforms, we determined susceptibility to spontaneous and induced acute colitis in mice lacking either the COX-1 or COX-2 isoform. We treated wild-type, $\mathrm{COX}-1^{-/}, \mathrm{COX}-2^{-/}$, and heterozygous mice with dextran sodium sulfate (DSS) to provoke acute colonic inflammation, and we quantified tissue damage, prostaglandin (PG) $\mathrm{E}_{2}$, and interleukin-1 $\beta$. No spontaneous gastrointestinal inflammation was detected in mice homozygous for either mutation, despite almost undetectable basal intestinal $\mathrm{PGE}_{2}$ production in $\mathrm{COX}-1^{-/-}$mice. Both $\mathrm{COX}-1^{-/-}$and $\mathrm{COX}-2^{-/-}$mice showed increased susceptibility to a low-dose of DSS that caused mild colonic epithelial injury in wild-type mice. $\mathrm{COX}-2^{-/-}$mice were more susceptible than COX-1 $1^{-/}$mice, and selective pharmacologic blockade of COX-2 potentiated injury in $\mathrm{COX}-1^{-/-}$mice. At a high dose, DSS treatment was fatal to $50 \%$ of the animals in each mutant group, but all wild-type mice survived. DSS treatment increased $\mathrm{PGE}_{2}$ intestinal secretion in all groups except $\mathrm{COX}-2^{-/-}$mice. These results demonstrate that COX-1 and COX-2 share a crucial role in the defense of the intestinal mucosa (with inducible COX-2 being perhaps more active during inflammation) and that neither isoform is essential in maintaining mucosal homeostasis in the absence of injurious stimuli.

J. Clin. Invest. 105:469-478 (2000).

\section{Introduction}

The function of the 2 cyclooxygenase (COX) isoforms, COX-1 and COX-2, in maintaining mucosal homeostasis and modulating inflammation in the digestive tract remains uncertain. Enzymatic activities of these COX isoforms produce prostaglandins (PGs) that play a proinflammatory role by mediating fever, hyperalgesia, vascular permeability, and edema; they also stimulate diarrhea by promoting chloride secretion and blocking sodium absorption in epithelial cells (1). During inflammation, dramatic increases in mucosal PG synthesis correlate with the disease activity of human inflammatory bowel diseases and experimental colitis $(2-4)$. However, PGs also play a protective role against gastrointestinal injury (5) and downregulation of the expression of proinflammatory cytokines $(6,7)$. Indeed, experimental colitis can be attenuated by pretreatment with exogenous PGs $(3,8)$, and prostaglandin $\mathrm{E}_{2}\left(\mathrm{PGE}_{2}\right)$ plays a major role in the regeneration of the epithelial crypts after dextran sodium sulfate (DSS)- and radiation-induced intestinal damage in mice (9). Further- more, inhibition of PG synthesis by indomethacin induces acute and chronic enterocolitis in genetically susceptible rats (10), which is in agreement with gastrointestinal ulceration seen in patients treated with nonsteroidal anti-inflammatory drugs (NSAIDs) (11, 12). This effect is attributed to the inhibition of constitutive mucosal PGs, which have cytoprotective properties (13). Similarly, active or passive immunization with $\mathrm{PGE}_{2}, \mathrm{PGE}_{1}$, and prostacyclin $\left(\mathrm{PGI}_{2}\right)$ induces gastrointestinal ulcers in rabbits $(14,15)$.

The relative contribution of COX-1 and COX-2 isoforms to the biologic activities of PGs in the gastrointestinal mucosa is less clear. Several observations led to the hypothesis that inducible COX-2 drives the proinflammatory actions of PGs during mucosal injury, whereas COX-1 regulates gastrointestinal homeostasis through the synthesis of cytoprotective PGs (16). COX1 is responsible for the basal production of PGs under normal gastric conditions (17), and its expression is not affected by corticosteroids (18). In mice, COX-1 has been reported to play a protective role against small 
intestinal (9) and colonic (19) mucosal injury through the synthesis of PGs that promote epithelial regeneration. In contrast, COX-2 expression is induced during inflammation (17), and its expression is inhibited by endogenous glucocorticoids (18).

COX-2 gene and protein expression is stimulated in macrophages and other cell types by proinflammatory cytokines like IL-1 (20) and TNF- $\alpha(21,22)$. This process is mediated in colonic epithelial cells by the activation of the nuclear factor NF- $\mathrm{KB}$ (23). COX-2 overexpression in rat intestinal epithelial cells inhibits the expression of cytoprotective heat-shock proteins (24). Based on these observations, some researchers have attributed the anti-inflammatory action of NSAIDs to the inhibition of COX-2; and harmful effects of NSAIDs on the gastrointestinal mucosa are attributed to the blockade of COX-1 activity $(25,26)$. This association of COX-2 with inflammatory events led to the development of selective COX-2 inhibitors expected to display systemic anti-inflammatory properties, while avoiding gastrointestinal toxicity.

Selective COX-2 inhibitors reduce air pouch and foot pad experimental inflammation in animal models without causing gastrointestinal injury, in contrast to classical NSAIDs $(27,17)$. Recently, a clinical trial in patients with osteoarthritis emphasized the safety of the selective COX-2 inhibitor rofecoxib, which caused significantly less gastroduodenal ulceration than the NSAID ibuprofen (28). However, COX-2 inhibitors have also been shown to be harmful when there is preexisting gastrointestinal inflammation, because they delay gastric ulcer healing in mice (29) and exacerbate colonic mucosal inflammation in rats (30). These toxic effects suggest a protective role for mucosal COX-2 in gastrointestinal inflammation.

COX-1 mediates epithelial regeneration in a model of irradiation-induced intestinal injury in mice (9), which supports the cytoprotective role attributed to COX-1 in gastrointestinal inflammation. However, COX-1-deficient mice do not exhibit any evidence of spontaneous gastric injury in the absence of an inflammatory stimulus and, surprisingly, are more resistant than their wild-type (WT) littermates to indomethacin-induced gastric damage (31). These observations, and the fact that the majority of patients receiving NSAIDs do not develop clinically significant gastrointestinal ulcerations, suggest that COX-1 does not exclusively mediate gastrointestinal protection, and instead it acts in concert with other redundant, protective molecules.

The aim of this study was to investigate the relative roles of COX-1 and COX-2 isoforms in spontaneous and induced inflammation of the intestinal mucosa. So far, all the studies related to the function of COX-1 and COX-2 in intestinal inflammation have involved pharmacologic inhibitors, which may not be entirely selective and have potential nonspecific side effects. As a complementary approach to selective pharmacologic blockade, we used mice genetically lacking either COX1 (31) or COX-2 (32) expression. We investigated the presence of spontaneous colitis as well as the relative severity of acute DSS-induced colitis in the absence of each of the COX isoforms; we compared heterozygous and WT littermates and the inhibition of both COX isoforms by partial pharmacologic blockade of COX$2^{-/-}$in $\mathrm{COXX}^{-1^{-/}}$mice.

\section{Methods}

Mice. WT, COX-1-/- homozygous, COX-1 $1^{+/}$heterozygous, $\mathrm{COX}-2^{-1-}$ homozygous, and $\mathrm{COX}-2^{+/-}$heterozygous outbred C57black6/SV129 mice were maintained on a 12hour light/dark schedule in filter top isolators with autoclaved water under specific pathogen-free (SPF) conditions, and fed autoclaved standard laboratory chow ad libitum. Genotypes of mice were determined on DNA isolated from tails, using previously described protocols $(31,32)$. Genomic DNA totaling $8-10 \mu \mathrm{g}$ was digested with BamHI (COX-1) or SacI (COX-2) overnight and applied to a $0.8 \%$ agarose gel. After separation using agarose gel electrophoresis, the DNA was transferred to Hybond nylon membrane. Membranes were probed with ${ }^{32} \mathrm{P}$-labeled specific probes for COX-1 or COX-2. Membranes were then washed and exposed overnight to Kodak XAR film (Eastman Kodak, Rochester, New York, USA) with an intensifying screen.

Assessment of spontaneous gastrointestinal inflammation. Clinical observations (twice weekly) included evaluation of body weight, diarrhea, occult blood in the stools (Hemoccult testing; SmithKline Beecham Pharmaceuticals, Philadelphia, Pennsylvania, USA), and perianal inflammation. Mice were killed at 4 different ages $(4,8$, 12 , and 16 weeks). Blinded gross observations and coded histology scores were performed on the colon, cecum, distal ileum, proximal jejunum, and stomach (glandular and squamous regions). Tissue IL- $1 \beta$ concentrations were evaluated by ELISA (Genzyme Pharmaceuticals, Cambridge, Massachusetts, USA) and tissue PGE $\mathrm{P}_{2}$ concentrations by RIA (PerSeptive Biosystems, Framingham, Massachusetts, USA) in snap-frozen tissues homogenized in PBS buffer containing the following antiproteases: $50 \mu \mathrm{g} / \mathrm{mL}$ antipain-dihydrochloride, $2 \mu \mathrm{g} / \mathrm{mL}$ aprotinin, and $0.5 \mu \mathrm{g} / \mathrm{mL}$ leupeptin (Roche Molecular Biochemicals, Indianapolis, Indiana, USA).

Induction of acute colitis. Mice 12-15 weeks old were fed DSS (TdB Consultancy AB, Uppsala, Sweden) in their drinking water, according to the protocol of Cooper et al. (33). Three separate studies were conducted. In the first (high-dose DSS), the survival rate was evaluated in 5 WT, $6 \mathrm{COX}-1^{-/-}, 7 \mathrm{COX}-1^{+/-}, 6 \mathrm{COX}-2^{-/-}$, and $8 \mathrm{COX}-2^{+/-}$ mice treated with high-dose DSS (10\%) continuously administered in the drinking water for 5 days. In the second (low-dose DSS), 14 WT, 7 COX-1-1-, 7 COX-2-/, 15 COX $-1^{+-}$, and $11 \mathrm{COX}^{-2^{+/-}}$mice received a low dose of DSS (2.5\%) for 5 days. Control groups consisting of 6 WT, $5 \mathrm{COX}-1^{+-}, 3 \mathrm{COX}-2^{+-}$, and $2 \mathrm{COX}-2^{-/-}$mice were fed water without DSS. The third (pharmacologic inhibition of COX-2 in COX-1-1- mice), the selective COX-2 inhibitor NS-398 (Cayman Chemical, Ann Arbor, Michigan, USA) was administered to WT, $\mathrm{COX}-1^{-/}$, and $\mathrm{COX}-$ 
$2^{-/-}$mice starting 2 hours before treatment with $2.5 \%$ DSS for 5 consecutive days until the end of DSS treatment. Control WT, COX-1-1-, and COX-2-/- mice treated with $2.5 \%$ DSS received the vehicle for NS-398 under the same conditions. Ten to 15 mice per group were used. NS-398 was dissolved in DMSO and the stock solution was diluted in saline just before administration. NS-398 $(1 \mathrm{mg} / \mathrm{kg})$ was injected intraperitoneally every 8 hours following a previously described protocol that reported significant inhibition of colonic $\mathrm{PGE}_{2}$ production in DSS-treated mice (9).

Assessment of inflammation in DSS-treated mice. Daily clinical evaluations included measurement of water consumption and body weight, evaluation of stool consistency, and the presence of blood in the stools. A previously validated clinical score ranging from 0 to 4 (33) was calculated using the parameters of weight loss, stool consistency, and the presence or absence of fecal blood. Mice were killed at day 5, blood was collected by intracardiac puncture, and the liver and spleen weights were measured. The colon was removed and divided for histology and for evaluation of $\mathrm{PGE}_{2}$ and cytokine secretion. Peripheral blood hemoglobin content and white blood cell count were analyzed using a blood cell counter (Baker Instruments Corp., Allentown, Pennsylvania, USA) and hematocrits were measured by centrifugation of heparinized microcapillary tubes (Fisher Scientific Co., Pittsburgh, Pennsylvania, USA) at 10,000 rpm.

Histology. Samples of proximal colon $(2-3 \mathrm{~cm}$ from the ileocecal junction) were fixed in $10 \%$ buffered formalin and stained with hematoxylin and eosin. The histological examination was performed in a blinded fashion by 2 different coauthors (O. Morteau and L.A. Dieleman) using a scoring system previously validated and described (34). Three independent parameters were measured: severity of inflammation (0-3: none, slight, moderate, severe), depth of injury (0-3: none, mucosal, mucosal and submucosal, transmural), and crypt damage (0-4: none, basal 1/3 damaged, basal 2/3 damaged, only surface epithelium intact, entire crypt and epithelium lost). The score of each parameter was multiplied by a factor reflecting the percentage of involvement (1-4: 0\%-25\%, 26\%-50\%, 51\%-75\%, $76 \%-100 \%)$ and added. The maximum possible score is 40 . In addition, the actual percentage of mucosal surface area ulcerated was estimated.

$P G E_{2}$ and cytokine secretion. The stomach, cecum, and colon were removed, opened longitudinally, washed in PBS buffer containing penicillin, streptomycin, and fungizone $(\mathrm{P} / \mathrm{S} / \mathrm{F}, 100 \mathrm{U} / \mathrm{mL})$, and then kept in cold serum-free media (RPMI $16401 \times$ with $\mathrm{P} / \mathrm{S} / \mathrm{F}$ ). The organs were cut into small pieces in a Petri dish containing fresh media, and $100 \mathrm{mg}$ of tissue fragments were incubated at $37^{\circ} \mathrm{C}$ in $1 \mathrm{~mL}$ of fresh media for 24 hours as described (35). Culture supernatants were harvested and assayed for $\mathrm{PGE}_{2}$ secretion by RIA (PerSeptive Biosystems) and for IL- $1 \beta$ and IL-10 secretion by ELISA (Genzyme Pharmaceuticals).
Statistical analysis. The data were expressed as the mean \pm SEM. Parametric data were analyzed using the nonpaired Student's $t$-test: a $P<0.05$ was considered significant. Nonparametric data were analyzed by ANOVA.

\section{Results}

Genetic absence of either COX-1 or COX-2 expression does not affect the integrity of the normal gastrointestinal mucosa. None of the mice exhibited any clinical manifestations (diarrhea, rectal bleeding, rectal prolapse, fecal occult blood, or anemia) associated with spontaneous gastrointestinal inflammation. No abnormalities were observed during gross examination of the gastrointestinal tract (glandular and squamous parts of the stomach, duodenum, jejunum, ileum, cecum, colon, and rectum) from WT, COX-1-, or COX-2-deficient mice. Blinded histologic observation of the same organs did not reveal any evidence of mucosal or submucosal inflammation or epithelial injury. Colonic myeloperoxidase activity was similar in the WT and knockout mice (data not shown), consistent with the absence of neutrophils in both groups. However, 2 out of the 10 COX-2-deficient mice developed peritonitis associated with serosal infiltration by mononuclear cells and neutrophils. This peritonitis has been previously observed in COX-2-deficient mice, but not in COX-1-deficient mice (32). Histologic evidence of mucosal inflammation was not found in these 2 mice.

Basal PGE $E_{2}$ but not IL-1 $\beta$ production is altered in the intestine of mice lacking COX-1. $\mathrm{PGE}_{2}$ in colonic tissues from $C O X$ $1^{-/-}$mice was barely detectable and significantly $(P<$ $0.01)$ lower than in colonic tissues from WT or COX-2-/mice, which showed similar $\mathrm{PGE}_{2}$ production (Figure 1). A similar lack of constitutive $\mathrm{PGE}_{2}$ production was observed in the stomach, duodenum, jejunum, ileum, and cecum of $\mathrm{COX}-1^{-/-}$mice, whereas levels were normal in $C O X-2^{-/-}$mice (data not shown). Basal IL-1 $\beta$ production was very low in the different segments of the gas-

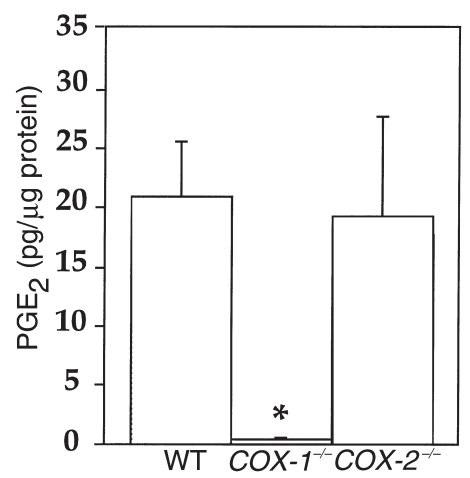

\section{Figure 1}

Basal $\mathrm{PGE}_{2}$ concentration in unstimulated colonic tissues from WT and COX-1- and COX-2-deficient mice. Tissue $\mathrm{PGE}_{2}$ concentrations were measured by RIA in snap-frozen tissues homogenized in PBS buffer containing the following antiproteases: $50 \mu \mathrm{g} / \mathrm{mL}$ antipaindihydrochloride, $2 \mu \mathrm{g} / \mathrm{mL}$ aprotinin, and $0.5 \mu \mathrm{g} / \mathrm{mL}$ leupeptin. Mean $\pm \mathrm{SEM}, n=7{ }^{*} P<0.05$ versus WT and $\mathrm{COX}-2^{-/-}, n=7$. 


\section{Table 1}

Survival rate (\%) with high-dose (10\%) DSS treatment administered for 5 days to either wild-type mice or mice homozygous (-/-) or heterozygous (+/-) for COX-1 or COX-2 deficiency

\begin{tabular}{lcc} 
Genotype & \multicolumn{2}{c}{$\%$ survival } \\
& 4 days & 5 days \\
WT & $100(5 / 5)$ & $100(5 / 5)$ \\
COX-1-/- & $100(6 / 6)$ & $50(3 / 6)$ \\
COX-2 & $83(5 / 6)$ & $50(3 / 6)$ \\
COX-1 & $100(7 / 7)$ & $86(6 / 7)$ \\
COX- $2^{+-}$ & $100(8 / 8)$ & $100(8 / 8)$ \\
\hline
\end{tabular}

Five to 8 mice per group were given 10\% DSS in drinking water continuously for 5 days, and survival was monitored.

trointestinal tract and was similar in all mice, regardless of tissue $\mathrm{PGE}_{2}$ levels (data not shown). These data confirm the lack of spontaneous gastrointestinal inflammation in SPF mice lacking constitutive mucosal $\mathrm{PGE}_{2}$, and they support the notion that constitutive expression of COX-1 is required for basal production of $\mathrm{PGE}_{2}$.

High-dose DSS treatment reduces survival in mice genetically lacking COX-1 or COX-2 expression. Treatment with highdose (10\%) DSS in the drinking water induced fulminant colitis characterized by the dramatic appearance of bloody diarrhea. Loss of body weight was significantly $(P$ $<0.05$ ) but transiently greater on day 3 in $\mathrm{COX}-2^{-/-}$mice, when compared with other DSS-treated groups: loss of $12.1 \pm 2.4 \%$ of original weight $\left(\mathrm{COX}-2^{-/-}\right), 4.9 \pm 1.7 \%$ (WT), $2.8 \pm 1.4 \%\left(\mathrm{COX}_{-1} 1^{-/-}\right), 4.9 \pm 1.2 \%\left(\mathrm{COX}-1^{+/-}\right)$, and $5.3 \pm 0.8 \%$ $\left(\mathrm{COX}-2^{+-}\right)$. The clinical inflammatory score was also significantly, but transiently (days 1 and 2), higher in the COX-2-/- mice when compared with DSS-treated WT: 1.3 $\pm 0.4\left(\mathrm{COX}-2^{---}\right)$versus $0.6 \pm 0.1$ (WT) $(P<0.05)$ (day 1$) ; 2.2$ $\pm 0.3\left(\mathrm{COX}-2^{--}\right)$versus $1.1 \pm 0.3$ (WT) $(P<0.05)$ (day 2$)$. The percentage survival of $\mathrm{COX}-2^{-/-}$and $\mathrm{COX}-1^{-/-}$mice decreased by day 4 , dropped by day 5 to $50 \%$ (Table 1 ) and was slightly decreased in the $\mathrm{COX}-1^{+/-}$heterozygous mice; whereas all WT and $\mathrm{COX}-2^{+-}$mice survived the full 5 days of treatment. These results suggest that the onset of severe colitis is accelerated in $\mathrm{COX}-2^{-/-}$mice, and that mice lacking either inducible or constitutive COX isoforms

\footnotetext{
Figure 2

Colonic $\mathrm{PGE}_{2}$ levels in 24-hour culture supernatants from either untreated mice (water controls) or WT, heterozygous, or homozygous mice for COX-1 or COX-2 deletion treated for 5 days with $10 \%$ DSS. The colons were removed, opened longitudinally, washed in PBS buffer containing penicillin, streptomycin, and fungizone $(P / S / F$, $100 \mathrm{U} / \mathrm{mL}$ ) and kept in cold serum-free media (RPMI $16401 \times$ with $\mathrm{P} / \mathrm{S} / \mathrm{F}$ ). The organs were cut into small pieces in a Petri dish containing fresh media and $100 \mathrm{mg}$ of tissues were incubated at $37^{\circ} \mathrm{C}$ in $1 \mathrm{~mL}$ of fresh media for 24 hours. Culture supernatants were harvested and assayed for $\mathrm{PGE}_{2}$ secretion by RIA. Mean $\pm \mathrm{SEM}, n=6$. ${ }^{*} P$ $<0.05$ versus water controls; ${ }^{+} P<0.05$ versus $\mathrm{COX}-1^{+/-}$.
}

have increased mortality when compared with WT mice.

Genetic absence of COX-2 prevents the increase in colonic $P G E_{2}$ secretion induced by high-dose DSS treatment. DSS treatment $(10 \%)$ evoked at day 5 an increase in $\mathrm{PGE}_{2}$ colonic secretion in all DSS-treated groups except in the $\mathrm{COX}-2^{-/-}$mice, when compared with water-treated negative controls (Figure 2). Colonic secretion of $\mathrm{PGE}_{2}$ was significantly $(P<0.01)$ decreased in $\mathrm{COX-2^{-/- }}$ mice and attenuated in the $10 \%$ DSS-treated $\mathrm{COX}-2^{+} /-$mice (Figure 2). Similar observations were made in the inflamed cecum. However, gastric $\mathrm{PGE}_{2}$ secretion was not increased in any of the DSS-treated mice (not shown). These results confirm the lack of inducible $\mathrm{PGE}_{2}$ secretion with colonic inflammation in $\mathrm{COX}-2^{-/-}$ mice and demonstrate an intermediate phenotype for COX-2 heterozygous mice.

Genetic absence of COX-1 or COX-2 expression exacerbates clinical abnormalities induced by low-dose DSS treatment. Low-dose (2.5\%) DSS treatment of WT mice for 5 days was associated with no significant alterations in body weight (Figure 3a) and only mild alterations in stool consistency with no fecal blood or mortality. Water consumption was similar in all groups (not shown). A significant $(P<0.01)$ decrease in weight was observed in the COX-2-/ mice on days 4 and 5 when compared with the WT mice (Figure 3a). It is interesting to note that COX$1^{+/-}$and $\mathrm{COX}_{-2} 2^{+/-}$mice exhibited a nonsignificant decrease in body weight by day $4\left(\mathrm{COX}-1^{+/-}: 1.2 \pm 1.0 \%\right.$, COX $-2^{+/}: 2.3 \pm 1.7 \%$, and WT: $0.2 \pm 1.0 \%$, which suggests an intermediate phenotype in those mice.

The clinical score based on weight loss, stool consistency, and presence of fecal blood was highest in the COX-2 $2^{-/}$mice receiving low-dose DSS (Figure $3 \mathrm{~b}$ ), reaching statistical significance when compared with the WT mice $(P<0.01$ from day 2 to day 5$)$. COX-1-1mice also exhibited a significantly greater $(P<0.01)$ clinical score than the WT mice on days 4 and 5 , but they had a lower clinical score than the $\mathrm{COX}-2^{-/-}$mice $(P<0.05$ at day 2$)$. The clinical score was significantly $(P<0.05)$ higher in the COX-2 $2^{+-}$heterozygous mice than in the WT mice at day $4(1.3 \pm 0.3$ versus $0.7 \pm 0.1$,

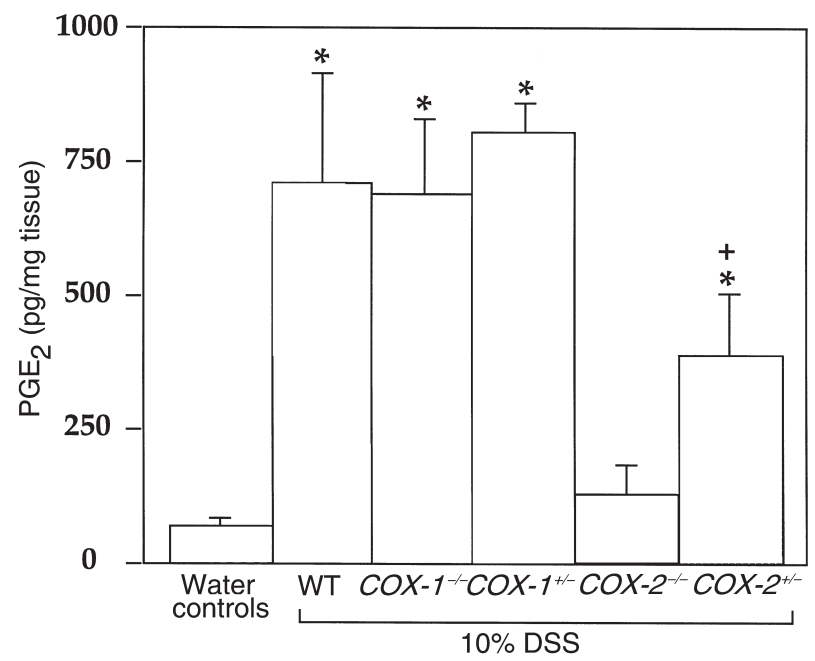


a

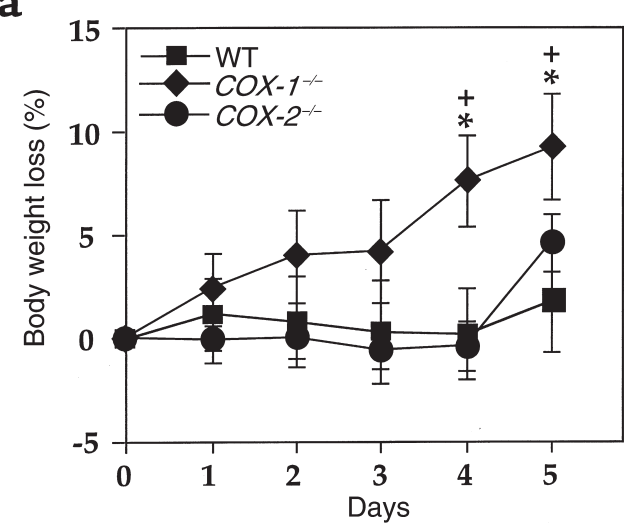

b

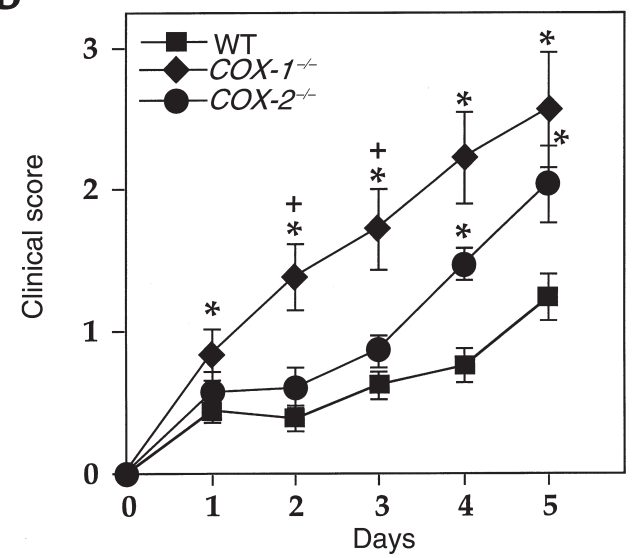

Figure 3

Body weight loss (a) and clinical score (b) induced by low-dose (2.5\%) DSS oral treatment in WT, COX-1/-- , and $\mathrm{COX}_{-2^{-/-}}$mice. Mean \pm SEM, $n=7 .{ }^{*} P<0.05$ versus $\mathrm{WT} ;{ }^{+} P<0.05$ versus $\mathrm{COX}^{-1}{ }^{-1-}$.

$P<0.05)$. In addition, the clinical score was significantly increased in the $\mathrm{COX}-1^{+/-}$heterozygous mice, when compared with the WT mice at day $2(0.8 \pm 0.1$ versus $0.4 \pm 0.1, P<0.05)$, day $4(1.3 \pm 0.2$ versus $0.7 \pm$ $0.1, P<0.01)$, and day $5(2.0 \pm 0.2$ versus $1.1 \pm 0.2, P<$ $0.01)$. These results demonstrate a greater degree of induced colitis in mice lacking COX-1 or COX-2 gene expression with an intermediate disease in mice heterozygous for either COX isoform.

Genetic deficiency in COX-1 or COX-2 expression induces macroscopic changes after low-dose DSS treatment. Macroscopic changes classically associated with DSS treatment, including shortening of the colon, increase in colonic weight and thickness, and increase in spleen weight (36), were not seen in WT mice treated with low-dose $(2.5 \%)$ DSS (Table 2). However, colonic shortening and splenomegaly were significantly increased in DSS-treated COX$1^{-/-}$and $\operatorname{COX}-2^{-/-}$mice $(P<0.05$ and $P$ $<0.01$, respectively), and the colon weight/length ratio, a measurement indicative of colonic edema and/or hyperplasia, was significantly increased in DSS-treated COX-2 $-1-$ mice $(P<0.05)$ when compared with DSStreated WT mice (Table 2). Consistent with clinical scores, COX-2-/- mice exhibited the most aggressive injury, with intermediate values for $\mathrm{COX}^{-1^{-/}}$mice treated with low-dose DSS.

Genetic deletion of COX-2 expression exacerbates hematologic alterations induced by low-dose DSS treatment. At day 5 , all groups of mice treated with low-dose $(2.5 \%)$ DSS exhibited a significant $(P<0.05)$ increase in peripheral blood white blood cells when compared with water controls (Table 2). COX-2-/- mice exhibited a significant $(P<0.05)$ increase in leukocytosis and anemia relative to DSS-treated COX-1-1- and WT mice (Table 2).

Histologic examination confirms the relative severity of disease induced by low-dose DSS. Blinded histologic injury scores were quantified in the proximal colon from DSS-treated (2.5\%) WT, COX-1-1- and COX-2-/- mice (6 mice per group). DSS administration induced focal inflammation in WT mice with shortening of the crypts and small discrete ulcers (Figure 4b). Mucosal injury was more aggressive in DSS-treated $\mathrm{COX}-2^{-/-}$ mice and was intermediate in COX-1-/- mice (Figure 4, $\mathrm{c}$ and $\mathrm{d}$, Table 3). The most reproducible histologic abnormalities in DSS-treated mice were crypt damage, which was significantly worse in $\mathrm{COX}-1^{-/-}$and $\mathrm{COX}-2^{-/-}$ mice compared with WT littermates, and depth of injury, which was increased in COX-2-/- mice (Table 3). The total histologic score was highest in DSS-treated COX-2-/- mice with a significant increase over WT mice $(P<0.05$, Table 3$)$. These observations confirm the gross findings (Table 2) and indicate that low-dose DSS induces more active mucosal damage in COX-2-deficient mice with intermediate injury in $\mathrm{COX}^{-1^{-/}}$mice.

Genetic lack of COX-2 is associated with decreased colonic production of $\mathrm{PGE}_{2}$ and increased IL- $1 \beta$ colonic production after low-dose DSS treatment. COX-2-/- mice treated with $2.5 \%$ DSS displayed a significant $(P<0.05)$ decrease in colonic $\mathrm{PGE}_{2}$ production (Figure $5 \mathrm{a})$ associated with a significant $(P<0.05)$ increase in colonic IL- $1 \beta$ secretion (Figure $5 b$ ), when compared with DSS-treated WT mice. The ratio of protective $\mathrm{PGE}_{2} /$ proinflammatory IL- $1 \beta$ was significantly

\section{Table 2}

Colon, spleen, and hematologic changes in wild-type mice and mice homozygous (-/-) for COX-1 or COX-2 deficiency treated with low-dose (2.5\%) DSS (day 5 of treatment)

\begin{tabular}{|c|c|c|c|c|c|}
\hline & $\begin{array}{c}\text { Colon length } \\
(\mathrm{mm})\end{array}$ & $\begin{array}{l}\text { h Colon } \\
\text { weight } / \text { length } \\
\text { ratio }(\mathrm{mg} / \mathrm{cm})\end{array}$ & $\begin{array}{c}\text { Spleen weight } \\
\text { (\% } \\
\text { body weight) }\end{array}$ & $\begin{array}{l}\text { White blood cells } \\
\qquad\left(\times 10^{-3} / \mu \mathrm{L}\right)\end{array}$ & $\begin{array}{c}\text { Hematocrit } \\
(\%)\end{array}$ \\
\hline $\begin{array}{l}\text { Water } \\
\text { controls }(n=9)\end{array}$ & $81 \pm 3$ & $26.2 \pm 1.3$ & $0.28 \pm 0.02$ & $3.7 \pm 0.4$ & $52.0 \pm 1.0$ \\
\hline $\begin{array}{l}\text { DSS-treated } \\
\text { wild-type }(n=6)\end{array}$ & $73 \pm 3$ & $28.4 \pm 1.3$ & $0.29 \pm 0.02$ & $8.9 \pm 0.6^{\mathrm{B}}$ & $50.6 \pm 0.7$ \\
\hline $\begin{array}{l}\text { DSS-treated } \\
\text { COX-1-1- }(n=6)\end{array}$ & $78 \pm 4$ & $32.8 \pm 4.0$ & $0.42 \pm 0.05^{\mathrm{A}, \mathrm{B}}$ & $10.0 \pm 1.1^{\mathrm{B}}$ & $48.6 \pm 2.2$ \\
\hline $\begin{array}{l}\text { DSS-treated } \\
\text { COX-2-/- }(n=6)\end{array}$ & $62 \pm 2^{A, B}$ & $34.4 \pm 2.5^{\mathrm{A}, \mathrm{B}}$ & $0.52 \pm 0.04 \mathrm{~A}, \mathrm{~B}$ & $17.7 \pm 5.5^{\mathrm{A}, \mathrm{B}}$ & $38.4 \pm 4.6^{\mathrm{A}, \mathrm{B}}$ \\
\hline
\end{tabular}



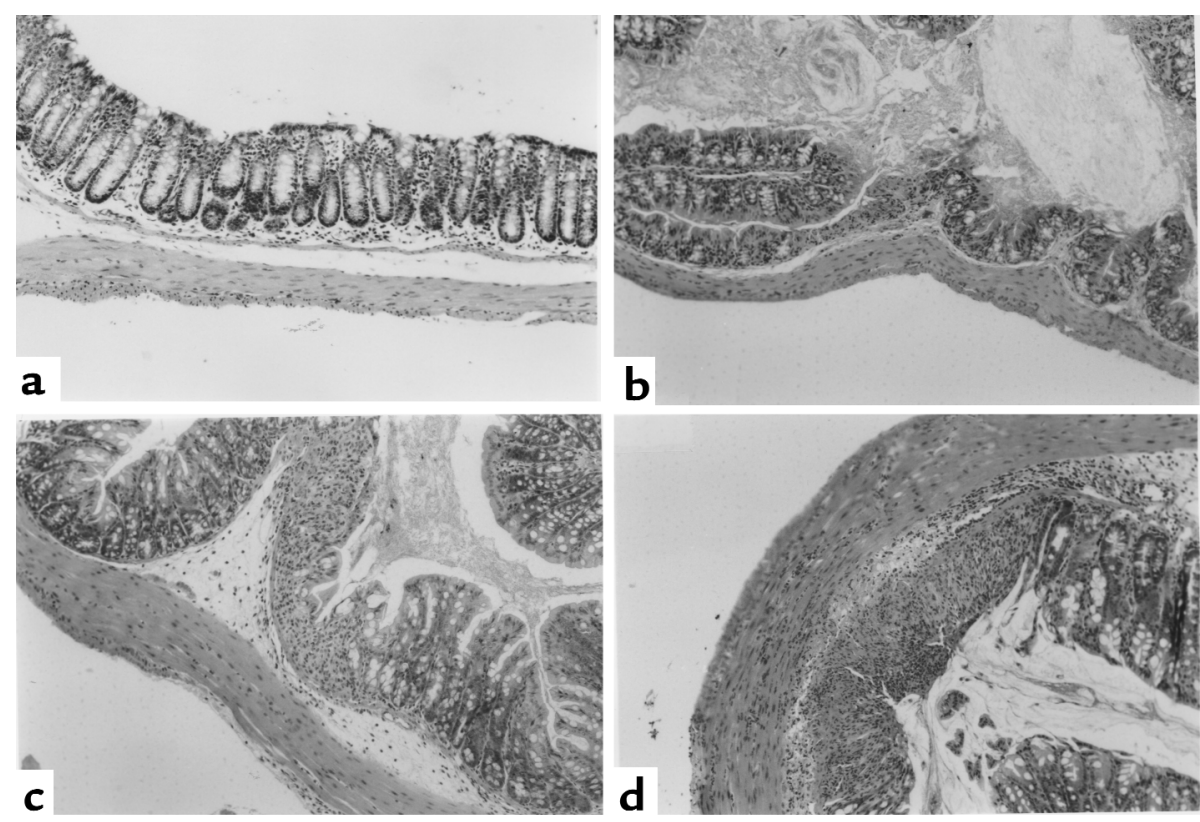

\begin{abstract}
Figure 4
Photomicrographs of the proximal colon of mice treated with low-dose DSS (2.5\%) or water only for 5 days, and a DSS-treated COX-1-1- mouse treated with the selective COX-2 inhibitor NS-398 ( $1 \mathrm{mg} / \mathrm{kg}$ every 8 hours) for 5 days. (a)WT mouse that received water (negative control) showing no mucosal damage. (b) WT mouse that received DSS for 5 days. Focal ulceration is present, but the majority of the mucosa shows no damage. (c) COX-1-/- mouse that received DSS developed a slightly larger mucosal ulcer. (d) $\mathrm{COX}-2^{-1-}$ mouse developed more extensive mucosal ulceration with inflammation extended into the submucosa. (e) $\mathrm{COX}_{-1^{-1-}}$ mouse that received NS-398 developed extensive colonic ulceration and inflammation. Magnification of all photomicrographs is $\times 33$.
\end{abstract}

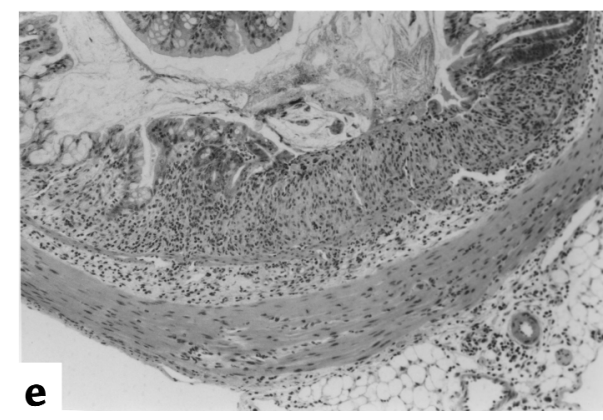

higher in DSS-treated WT mice $(128 \pm 20 \mathrm{WT} ; 18 \pm 4$ COX-2--, $P<0.01)$. $\mathrm{PGE}_{2}$ production was similar in WT and $\mathrm{COX}-2^{-/}$water controls. $\mathrm{PGE}_{2}$ secretion was not measured in $2.5 \%$ DSS-treated COX-1-/- mice because tissue $\mathrm{PGE}_{2}$ levels were no different from WT controls after high-dose (10\%) DSS treatment (Figure 2).

Partial inbibition of COX-2 by NS-398 exacerbates DSSinduced colitis in COX-1-deficient mice. Treatment with the selective COX-2 inhibitor NS-398 $(1 \mathrm{mg} / \mathrm{kg}$ every 8 hours) did not induce any significant change in the clinical or histologic scores of DSS-treated $(2.5 \%)$ WT and $\mathrm{COX}_{-2 /-}$ mice (data not shown). However, NS398 treatment consistently increased the clinical score in DSS-treated COX-1-/- mice when compared with vehicle-treated DSS-treated COX-1 $1^{-/}$after the first day of DSS administration (Figure 6); although the body weight loss component was not affected. NS-398 also evoked a $20 \%$ mortality rate in the COX$1^{-/-}$mice at day 5 of low-dose DSS treatment, whereas none of the vehicle-treated COX-1-/- mice died. The histologic score at day 5 of DSS treatment was considerably higher in $\mathrm{COX}-1^{-/-}$mice treated with NS398 than in similarly treated WT mice (WT $5.9 \pm 2.5$ versus $\left.C O X-1^{-/-} 14.5 \pm 1.9, P<0.01\right)$; it achieved levels comparable with COX-2-/- mice receiving DSS and NS-398 (15.6 \pm 0.9$)$. NS-398 increased colonic histologic scores $28 \%$ in $\mathrm{COX}^{-11^{-/}}$mice $(11.3 \pm 1.3$ vehicle;
$14.5 \pm 1.9$ NS-398) and increased the surface area ulcerated by histologic assessment by 53\% (14.3 \pm $4.3 \%$ vehicle versus $21.9 \pm 3.9$ NS-398). NS-398 partially inhibited the production of $\mathrm{PGE}_{2}$ by cultured colonic tissues (24 hours) in the DSS-treated COX1-deficient mice (vehicle treated: 3,583 $\pm 1,162 \mathrm{pg}$ $\mathrm{PGE}_{2} / \mathrm{mg}$ tissue versus NS-398 treated: 1,971 \pm 763 $\mathrm{pg} / \mathrm{mg} ; P=0.13)$. Furthermore, NS-398 did not inhibit colonic $\mathrm{PGE}_{2}$ production in the DSS-treated COX$2^{-/-}$mice (vehicle treated: $687 \pm 141 \mathrm{pg} \mathrm{PGE} / \mathrm{mg}$ tissue versus NS-398 treated: $595 \pm 29 \mathrm{pg} \mathrm{PGE}_{2} / \mathrm{mg}$ tissues), indicating that NS-398 did not affect COX1 activity at doses used. These results suggest that simultaneous inhibition of both constitutive (by COX-1 genetic deletion) and inducible (by partial pharmacologic inhibition by NS-398) COX isoforms further potentiates experimentally induced colitis.

\section{Discussion}

Our results demonstrate that genetic absence of either the COX-2 or COX-1 isoform exacerbates the severity of acute mucosal inflammation induced by a chemical agent that injures the colonic epithelial cells (33). Mice lacking COX-2 are more severely affected than those lacking COX-1 in this model, and pharmacologic inhibition of COX-2 potentiates disease in $\mathrm{COX}_{-11^{-/}}$mice. We also show that genetic lack of either COX-1 or 


\section{Figure 5}

PGE 2 levels (a) and IL-1 $\beta$ levels (b) in 24-hour culture supernatants of colonic tissues from untreated (water controls) or DSS-treated (2.5\%) WT and COX-2-/- mice. The colons were removed, opened longitudinally, washed in PBS buffer containing penicillin, streptomycin, and fungizone $(P / S / F$, $100 \mathrm{U} / \mathrm{mL}$ ), and kept in cold serum-free media (RPMI 1640 1x with $\mathrm{P} / \mathrm{S} / \mathrm{F})$. The organs were cut into small pieces in a Petri dish containing fresh media, and 100 $\mathrm{mg}$ of tissues was incubated at $37^{\circ} \mathrm{C}$ in $1 \mathrm{~mL}$ of fresh media for 24 hours. Culture supernatants were harvested and assayed for $\mathrm{PGE}_{2}$ secretion by RIA and for IL$1 \beta$ by ELISA (Genzyme Diagnostics). Mean \pm SEM, $n=7$. ${ }^{*} P<$ 0.05 versus $\mathrm{WT} ;{ }^{+} P<0.05$ versus water controls. a
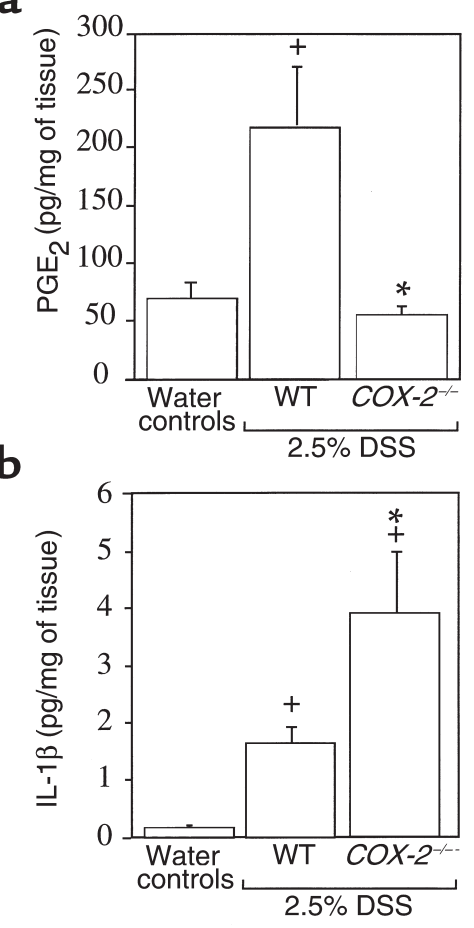

ing integrity in the gastrointestinal mucosa in the absence of a preexisting injury. However, our results do not exclude the possibility that the simultaneous absence of both COX-1 and COX-2 isoforms might endanger the integrity of the gastrointestinal mucosa, as recently hypothesized $(37,38)$.

Selective COX-2 deletion leads to enhanced susceptibility to low-dose DSS-induced injury relative to all other groups investigated. This correlated with a selective lack of increased colonic $\mathrm{PGE}_{2}$ levels with injury. COX-2 heterozygotes, which have a partial deficiency in inducible $\mathrm{PGE}_{2}$, displayed an intermediate phenotype. These results strongly support a protective role for inducible mucosal PGs during inflammation, which is in agreement with the reported ability of exogenous $\mathrm{PGE}_{2}$ to prevent experimental colitis (19). PGE $_{2}$ inhibits IL- 1 and TNF- $\alpha$ secretion by stimulated human (6) and murine (39) monocytes. This provides a mechanism of mucosal protection during inflammation and explains our observation of increased colonic IL-1 $\beta$ levels in $\mathrm{COX}-2^{-/-}$mice with DSS-induced colitis when compared with WT

COX-2 alone does not affect the integrity of the colonic mucosa in the absence of any inflammatory stimulus. These results suggest that intrinsic PGs, especially those induced during inflammation, have a protective role during intestinal injury.

Under basal conditions, native SPF mice lacking either the COX-1 or COX-2 isoform do not exhibit any clinical or histologic signs of spontaneous gastrointestinal inflammation, despite a marked deficiency in mucosal $\mathrm{PGE}_{2}$ contents in COX-1-deficient mice. Twenty percent of $\mathrm{COX}-2^{---}$mice developed peritonitis, but these mice had no associated mucosal damage by gross, histologic, or biochemical criteria. Our results agree with previous reports that COX1-deficient mice fail to develop gastritis (31), and that selective COX-2 inhibitors used at doses that inhibit arthritis and pulmonary inflammation do not affect the integrity of the normal gastric mucosa $(17,27$, 28). However, the lack of spontaneous gastrointestinal inflammation in $\mathrm{COX}^{-1^{-/-}}$mice (which have very low constitutive mucosal PG levels) does not agree with the results of Redfern et al. (15) who reported spontaneous gastric and colonic ulceration in rabbits passively immunized with anti-PGE $1,-\mathrm{PGE}_{2}$, and -prostacyclin antibodies. Gastrointestinal inflammation after NSAID exposure is probably the combined result of mucosal PG inhibition and direct epithelial toxicity (10). Our results argue against a compensatory increase in constitutive $P G$ production in COX-1-deficient mice, because basal $\mathrm{PGE}_{2}$ production was barely detectable in the gastrointestinal tract of these mice. Thus our data confirm that neither COX-1 nor COX-2 alone is essential in maintainmice, which displayed enhanced $\mathrm{PGE}_{2}$ production but relatively low IL- $1 \beta$ concentrations. Although deficient endogenous PGs could adversely affect platelet function and lead to increased fecal blood loss (which is 1 parameter of our clinical score) (33), our results clearly demonstrate enhanced colonic injury by objective clinical (weight loss, diarrhea, mortality), gross (colonic weight and length), biochemical (IL- $1 \beta$ secretion), and histologic criteria. The increase in colonic $\mathrm{PGE}_{2}$ that we demonstrated in tissue culture supernatants was not observed when $\mathrm{PGE}_{2}$ levels were measured in processed sections of frozen colonic tissues (data not shown). This is consistent with a recent observation that $\mathrm{PGE}_{2}$ in cecal tissues of DSS-treated mice does not increase during the treatment period, but rather increases significantly 3 days after cessation of DSS administration during the recovery (19).

Our findings agree with recent reports that selective inhibition of COX-2 exacerbates trinitrobenzene sulfonic acid-induced colitis in rats (30) and delays heal-

\section{Table 3}

Blinded histologic assessment of colonic injury in WT, COX-1-1-, and COX-2-/- mice treated with $2.5 \%$ DSS for 5 days

\begin{tabular}{lcccc}
\hline & $\begin{array}{c}\text { Percent of } \\
\text { surface } \\
\text { area ulcerated }\end{array}$ & $\begin{array}{c}\text { Depth of } \\
\text { tissue } \\
\text { injury }\end{array}$ & $\begin{array}{c}\text { Crypt } \\
\text { damage } \\
\text { score }^{\mathrm{A}}\end{array}$ & $\begin{array}{c}\text { Total } \\
\text { histologic } \\
\text { score }^{\mathrm{A}}\end{array}$ \\
$\mathrm{WT}(n=6)^{\mathrm{B}}$ & $12.5 \pm 5.5^{\mathrm{C}}$ & $2.1 \pm 0.5$ & $3.3 \pm 0.5$ & $8.6 \pm 1.6$ \\
$\mathrm{COX}-1^{-1-}(n=6)$ & $14.3 \pm 4.3$ & $2.9 \pm 0.4$ & $4.7 \pm 0.5^{\mathrm{D}}$ & $11.3 \pm 1.3$ \\
$\operatorname{COX}^{-2^{--}}(n=6)$ & $19.5 \pm 3.8$ & $4.2 \pm 0.5^{\mathrm{D}}$ & $4.6 \pm 0.4^{\mathrm{D}}$ & $12.6 \pm 1.2^{\mathrm{D}}$ \\
\hline
\end{tabular}

${ }^{A}$ Based on validated scoring system described in Methods section (34). ${ }^{B}$ For 1-4 sections per mouse, 6 mice/group. ${ }^{C}$ Mean \pm SEM. ${ }^{D} P<0.05$ versus WT mice. 


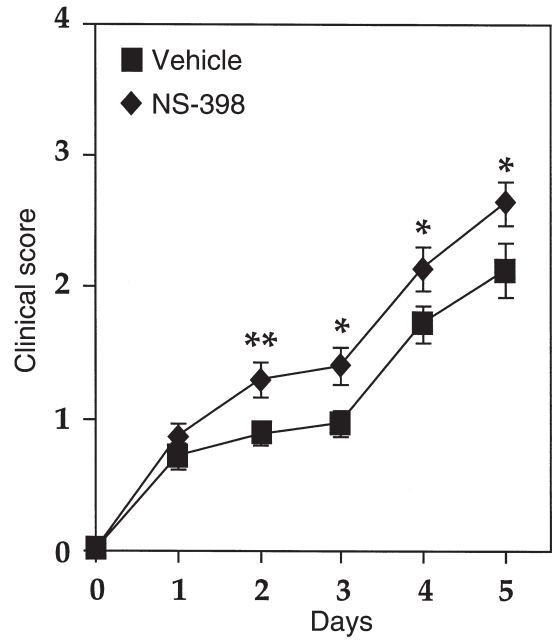

Figure 6

Effect of the selective COX-2 inhibitor NS-398 on the clinical score in $2.5 \%$ DSS-treated COX-1-/- mice. NS-398 $(1 \mathrm{mg} / \mathrm{kg})$ was injected intraperitoneally every 8 hours, leading to a cumulative dosage of 3 $\mathrm{mg} / \mathrm{kg}$ daily. NS-398 was administered starting 2 hours before treatment with $2.5 \%$ DSS and for 5 days consecutively until the end of DSS treatment. Control $\mathrm{COX}_{-1^{-1}}$ mice treated with $2.5 \%$ DSS were administered the vehicle for NS-398 under the same conditions. Ten to 15 mice per group were investigated. Mean \pm SEM. ${ }^{*} P<0.05$ versus vehicle-treated group; ${ }^{*} P<0.01$ versus vehicle-treated group.

ing of acetic acid-induced gastric ulcers in mice (29). Selective COX-2 inhibitors have no effect on small intestinal crypt survival after irradiation in mice (9). The absence of involvement of COX-2 in radiationinduced epithelial damage suggests that the mechanism of injury in that model is different from that triggered by DSS. A recent study showed that DSS treatment increases the number of COX-2-expressing lamina propria mononuclear cells, while COX-2 overexpression remains undetectable in the inflamed epithelium of those mice (19). Recent in vitro studies suggest that the role of COX-2 in mucosal injury is highly variable, depending on the nature of the injurious stimuli involved. Rat intestinal epithelial cells transfected with COX-2 exhibit a downregulation of inducible cytoprotective heat-shock proteins (24), which are involved in cell death inhibition $(40,41)$. In contrast, COX-2 overexpression in rat intestinal epithelial cells provides cellular resistance against butyrate-induced apoptosis (42).

Our COX-1-1- mice had almost undetectable basal $\mathrm{PGE}_{2}$ levels, but their colonic $\mathrm{PGE}_{2}$ concentrations were equal to those of WT controls after DSS-induced injury; they had an intermediate sensitivity to inflammation between WT and COX-2-/- mice. The disparity between $\mathrm{PGE}_{2}$ concentrations in homogenized colonic tissues and sensitivity to mucosal injury could be explained by differential production of other protective arachidonic acid metabolites (i.e., $\mathrm{PGE}_{1}$, prostacyclin, etc.); or it could be explained by a critically important role for constitutively produced $\mathrm{PGE}_{2}$ on epithelial restitution and protection against injurious agents. Cohn et al. showed that colonic COX-1 is primarily expressed by epithelial cells (9), and that COX-1 expression in colonic epithelial cells is diminished after DSS administration, probably secondary to loss of crypt epithelial cells (19). The former study demonstrated a key role for PGs regulated by COX-1 in mediating crypt stem cell survival after gamma irradiation in mice. Similarly, in the stomach, COX-1 plays an important role in resistance of the gastric mucosa to acute and chronic injury by endotoxin (43). These results suggest that constitutively produced PGs in gastrointestinal epithelial cells protect against a variety of injurious stimuli in an autocrine fashion. Inducible PG secretion by activated mononuclear and mesenchymal cells expressing COX-2 does not seem to entirely compensate for loss of epithelial COX-1 expression. However, COX-2-mediated $\mathrm{PG}$ production is clearly important, as demonstrated by the highly aggressive DSS-induced colitis in COX$2^{-/-}$mice and in $\mathrm{COX}-1^{-/-}$mice treated with the selective COX-2 inhibitor NS-398. It has been suggested that COX-2 plays a role in healing rather than in protection of the colonic mucosa, as in the gastric mucosa (44). This concept has been strongly suggested by a recent observation that cecal tissue $\mathrm{PGE}_{2}$ levels are increased during the recovery period after DSS treatment (19). However, it is likely that COX-2 also acts through complementary mechanisms. Recently, COX-2 has been reported to mediate oral immunologic tolerance to a dietary antigen in T-cell receptor mutant mice (45). In that model, high levels of COX-2-dependent PGs produced by lamina propria mononuclear cells act as immunomodulators in T-lymphocyte responses to the antigen. This observation suggests that COX-2 may promote mucosal protection by suppressing pathogenic cellular immune responses to luminal bacterial antigens that perpetuate intestinal inflammation (46).

Consistent with observations in a murine model of absent intestinal trefoil factor (47), biologic effects of COX isoform deficiency were more apparent at low-dose than high-dose DSS. The fulminant colitis induced by $10 \%$ DSS led to a $50 \%$ mortality rate in both COX-1- and COX-2-deficient mice, whereas responses to $2.5 \%$ DSS administration, which induced very mild inflammation in WT mice, indicated a more active protective role for COX-2 than for COX-1. However, both high- and lowdose DSS-induced injuries were worse in mice with selective blockade of constitutive or inducible PG synthesis than in WT controls.

Treatment with the selective COX-2 inhibitor NS-398 exacerbated low-dose DSS-induced colitis and enhanced mortality in $\mathrm{COX}^{-1^{-/}}$mice. This indicates an additive protective role for both COX-1 and COX-2 in this model. Inflammation and colonic $\mathrm{PGE}_{2}$ production in DSStreated COX-2-/- mice were not affected by NS-398 treatment, demonstrating that this COX-2 inhibitor did not substantially affect the activity of the COX-1 isoform. The absence of an effect of NS-398 on DSS-treated WT mice may be due to the partial inhibition of COX-2 
expression at doses used in this study, as compared with the total lack of inducible prostaglandins in the colons of $\mathrm{COX}-2^{-/-}$mutants.

Mice genetically deficient in either the COX-1 or COX-2 isoform may display compensatory metabolic pathways. For example, immortalized, nontransformed lung fibroblasts from $\mathrm{COX}-1^{-/-}$and $\mathrm{COX}-2^{-/-}$mice overexpress the remaining functional $\mathrm{COX}$ isoform in response to IL-1, leading to a relative increase in $\mathrm{PGE}_{2}$ production (48). These cells also overexpress cytosolic phospholipase A2 in both unstimulated and IL-1-stimulated conditions (48). However, we did not observe any increase in colonic $\mathrm{PGE}_{2}$ production in DSS-treated COX-2-/- mice, whereas both WT and COX-1 $1^{-/-}$mice exhibited significant increases. In addition, colonic tissues of $\mathrm{COX}-1^{-/-}$mice contained almost undetectable levels of $\mathrm{PGE}_{2}$ when compared with the colons from WT and $\mathrm{COX}-2^{-/-}$mice. These findings strongly suggest that there are no compensatory pathways induced in the colons of these knockout mice, although we cannot rule out such a possibility.

In conclusion, both COX-1 and COX-2 mediate protection against acute mucosal inflammation, because absence of either isoform exacerbates DSS-induced colitis, yet neither isoform is absolutely required for maintenance of mucosal homeostasis in the absence of injurious stimuli. Furthermore, simultaneous blockade of both isoforms by gene deletion of COX-1 and partial pharmacologic inhibition of COX-2 produced even greater injury, indicating an additive protective role for constitutive and inducible PGs. When relatively low doses of DSS were administered, COX-2-deficient mice had more aggressive colitis than $\mathrm{COX-1^{-/ }}$ mice, suggesting that inducible PGs may be relatively more important in modulating mucosal protection against colonic injury than constitutive PGs. The reciprocal relationship between mucosal $\mathrm{PGE}_{2}$ and IL- $1 \beta$ concentrations supports an inhibitory effect of $\mathrm{PGE}_{2}$ on proinflammatory cytokine production, whereas the beneficial effect of COX-1, which is predominantly produced by crypt epithelial cells (9), suggests a protective effect in epithelial integrity. In our model of acute colonic injury, COX-2-mediated PG production plays a beneficial rather than a proinflammatory role, suggesting that selective COX-2 pharmacologic inhibitors should be avoided in patients with established intestinal inflammation. Similar conclusions have been reached in a recent study showing that COX-2 exhibits anti-inflammatory properties in a rat model of pleurisy (49). The complex, interactive mechanisms of how constitutive and inducible PGs prevent intestinal inflammation remain to be determined. These mechanisms can be dissected using complementary approaches afforded by selective pharmacologic inhibitors and genetic deletion of COX-1 and COX-2 gene expression.

\section{Acknowledgments}

The authors thank Julie Vorobiov of the Immunoassay Core Facility of the University of North Carolina Cen- ter for Gastrointestinal Biology and Disease for performing the ELISA and RIA measurements, and Susie May for secretarial assistance. This study was supported by the National Institutes of Health grants DK 40249, DK 53347, and DK 34987, as well as by The Crohn's and Colitis Foundation of America.

1. Sartor, R.B., and Powell, D.W. 1991. In Diarrheal diseases. M. Field, editor. Elsevier Science. New York, NY. 75-114.

2. Sharon, P., Ligumsky, M., Rachmilewitz, D., and Zor, U. 1978. Role of prostaglandins in ulcerative colitis. Enhanced production during active disease and inhibition by sulfasalazine. Gastroenterology. 75:638-640.

3. Allgayer, H., Deschryver, K., and Stenson, W.F. 1989. Treatment with 16,16'-dimethyl $\mathrm{PGE}_{2}$ before and after induction of colitis with trinitrobenzene sulfonic acid in rats decreases inflammation. Gastroenterology. 96:1290-1300.

4. Rachmilewitz, D., et al. 1989. Inflammatory mediators of experimental colitis in rats. Gastroenterology. 97:326-327.

5. Hoult, J.R.S., and Moore, P.K. 1978. Sulphasalazine is a potent inhibitor of prostaglandin 15 hydroxydehydrogenase: possible basis for therapeutic action in ulcerative colitis. Br. J. Pharmacol. 64:6-8.

6. Knudsen, P.J., Dinarello, C.A., and Strom, T.B. 1986. Prostaglandin posttranscriptionally inhibit monocyte expression of interleukin 1 activity by increasing intracellular cyclic adenosine monophosphate. J. Immunol. 137:3189-3194.

7. Marcinkiewicz, J. 1991. In vitro cytokine release by activated murine peritoneal macrophages: role of prostaglandins in the differential regulation of tumor necrosis factor $\alpha$, interleukin 1 and interleukin 6. Cytokine. 3:327-332.

8. Fedorak, R.N., Empey, L.R., MacArthur, C., and Jewell, L.D. 1990. Misoprostol provides a colonic mucosal protective effect during acetic acidinduced colitis in rats. Gastroenterology. 98:615-625.

9. Cohn, S.M., Schloemann, S., Tessner, T., Seibert, K., and Stenson, W.F. 1997. Crypt stem cell survival in the mouse intestinal epithelium is regulated by prostaglandins synthesized through cyclooxygenase-1. J. Clin. Invest. 99:1327-1379.

10. Yamada, T., et al. 1993. Mechanisms of acute and chronic intestinal inflammation induced by indomethacin. Inflammation. 17:641-662.

11. Kaufmann, H.J., and Taubin, H.L. 1987. Nonsteroidal anti-inflammatory drugs activate quiescent inflammatory bowel disease. Ann. Intern. Med. 107:513-516.

12. Bjarnason, I., Hayllar, J., MacPherson, A.J., and Russell, A.S. 1993. Side effects of nonsteroidal anti-inflammatory drugs on the small and large intestine in humans. Gastroenterology. 104:1832-1847.

13. Wallace, J.L., Keenan, C.M., Gale, D., and Shoupe, T.S. 1992. Exacerbation of experimental colitis by NSAIDs is not related to elevated leukotriene B4 synthesis. Gastroenterology. 102:18-27.

14. Olson, G.A., Leffler, C.W., and Fletcher, A.M. 1985. Gastroduodenal ulceration in rabbits producing antibodies to prostaglandins. Prostaglandins. 29:475-480.

15. Redfern, J.S., Blair, A.J., Lee, E., and Feldman, M. 1987. Gastrointestinal ulcer formation in rabbits immunized with prostaglandin $\mathrm{E}_{2}$. Gastroenterology. 93:744-752.

16. Masferrer, J.L., Isakson, P.C., and Seibert, K. 1996. Cyclooxygenase-2 inhibitors: a new class of anti-inflammatory agents that spare the gastrointestinal tract. Gastroenterol. Clin. North Am. 25:363-372.

17. Seibert, K., et al. 1994. Pharmacological and biochemical demonstration of the role of cyclooxygenase 2 in inflammation and pain. Proc. Natl. Acad. Sci. USA. 91:12013-12017.

18. O'Banion, M.K., Sadowski, H.B., Winn, V., and Young, D.A. 1991. A serum- and glucocorticoid-regulated 4 kilobase mRNA encodes a cyclooxygenase-related protein. J. Biol. Chem. 266:23261-23267.

19. Tessner, T., Cohn, S., Schloemann, S., and Stenson, W.F. 1998. Prostaglandins prevent decreased epithelial cell proliferation associated with dextran sodium sulfate injury in mice. Gastroenterology. 115:874-882.

20. O’Banion, M.K., Miller, J.C., Chang, J.W., Kaplan, M.D., and Coleman, P.D. 1996. Interleukin 1 beta induces prostaglandin G/H synthase-2 (cyclooxygenase-2) in primary murine astrocyte culture. J. Neurochem. 66:2532-2540.

21. Baschwich, P.R., Chensue, S.W., Larrick, J.W., and Kunkel, S.L. 1986 Tumor necrosis factor stimulates interleukin-1 and prostaglandin $\mathrm{E}_{2}$ production in resting macrophages. Biochem. Biophys. Res. Commun. 136:94-101.

22. Lehmann, V., Benninghoff, B., and Droge, W. 1988. Tumor necrosis factor-induced activation of peritoneal macrophages is regulated by prostaglandin $\mathrm{E}_{2}$ and cAMP. J. Immunol. 141:587-591.

23. Jobin, C., Morteau, O., Han, D.S., and Sartor, R.B. 1998. Specific NFkappa B blockade selectively inhibits tumour necrosis factor-alpha- 
induced COX-2 but not constitutive COX-1 gene expression in HT-29 cells. Immunology. 95:537-543.

24. Ethridge, R.T., Hellmich, M.R., DuBois, R.N., and Evers, B.M. 1998. Inhibition of heat-shock protein 70 induction in intestinal cells overexpressing cyclooxygenase 2. Gastroenterology. 115:1454-1463.

25. Xie, W., Robertson, D.L., and Simmons, D.L. 1992. Mitogen-inducible prostaglandin G/H synthase: a new target for nonsteroidal anti-inflammatory drugs. Drug Dev. Res. 25:249-265.

26. Chan, C.C., et al. 1995. Pharmacology of a selective cyclooxygenase-2 inhibitor, L-745,337: a novel nonsteroidal anti-inflammatory agent with an ulcerogenic sparing effect in rat and nonhuman primate stomach. $J$. Pharmacol. Exp. Ther. 274:1531-1537.

27. Masferrer, J.L., et al. 1994. Selective inhibition of inducible cyclooxygenase. Proc. Natl. Acad. Sci. USA. 91:3228-3232.

28. Laine, L., et al. 1999. A randomized trial comparing the effect of rofecoxib, a cyclooxygenase 2 -specific inhibitor, with that of ibuprofen on the gastroduodenal mucosa of patients with osteoarthritis. Gastroenterology. 117:776-783.

29. Mizuno, H., et al. 1997. Induction of cyclooxygenase 2 in gastric mucosal lesions and its inhibition by the specific antagonist delays healing in mice. Gastroenterology. 112:645-648.

30. Reuter, B.K., Asfaha, S., Buret, A., Sharkey, K.A., and Wallace, J.L. 1996 Exacerbation of inflammation-associated colonic injury in rat through inhibition of cyclooxygenase-2. J. Clin. Invest. 98:2076-2085.

31. Langenbach, R., et al. 1995. Prostaglandin synthase 1 gene disruption in mice reduces arachidonic acid-induced inflammation and indomethacin-induced gastric ulceration. Cell. 83:483-492.

32. Morham, S.G., et al. 1995. Prostaglandin synthase 2 gene disruption causes severe renal pathology in the mouse. Cell. 83:473-482.

33. Cooper, H.S., Murthy, S.N.S., Shah, R.S., and Sedergran, D.J. 1993. Clinicopathologic study of dextran sulfate sodium experimental murine colitis. Lab. Invest. 69:238-249.

34. Dieleman, L.A., et al. 1998. Chronic experimental colitis induced by dextran sulphate sodium (DSS) is characterized by $\mathrm{TH}_{1}$ and $\mathrm{TH}_{2}$ cytokines. Clin. Exp. Immunol. 114:385-391.

35. Sellon, R.K., et al. 1998. Resident enteric bacteria are necessary for devel- opment of spontaneous colitis and immune system activation in interleukin-10-deficient. Infect. Immun. 66:5224-5231.

36. Axelsson, L.G., Landstrom, E., Bylund-Fellenius, A.C. 1998. Experimental colitis induced by dextran sulphate sodium in mice: beneficial effects of sulphasalazine and olsalazine. Aliment. Pharmacol. Ther. 12:925-934.

37. Stenson, W.F. 1997. Cyclooxygenase 2 and wound healing in the stomach. Gastroenterology. 112:645-648.

38. Wallace, J.L., et al. 1998. Cyclooxygenase 1 contributes to inflammatory responses in rats and mice: implications for gastrointestinal toxicity. Gastroenterology. 115:101-109.

39. Kunkel, S.L., Chensue, S.W., Phan, S.H. 1986. Prostaglandins as endogenous mediators of interleukin-1 production. J. Immunol. 136:186-192.

40. Samali, A., and Cotter, T.G. 1996. Heat shock proteins increase resistance to apoptosis. Exp. Cell Res. 223:163-170.

41. Tsujii, M., and DuBois, R.N. 1995. Alterations in cellular adhesion and apoptosis in epithelial cells overexpressing prostaglandin endoperoxidase synthase 2. Cell. 83:493-501.

42. Li, W.X., Chen, C.H., Ling, C.C., and Li, G.C. 1996. Apoptosis in heatinduced cell killing: the protective role of hsp-70 and the sensitization effect of the c-myc gene. Radiat. Res. 145:324-330.

43. Ferraz, J.G., et al. 1997. Induction of cyclooxygenase 1 and 2 in the rat stomach during endotoxemia: role in resistance to damage. Gastroenterology. 113:195-204.

44. Yeomans, N.D., Cook, G.A., and Giraud, A.S. 1998. Selective COX-2 inhibitors: are they safe for the stomach? Gastroenterology. 115:227-229.

45. Newberry, R.D., Stenson, W.F., Lorenz, R.G. 1999. Cyclooxygenase-2dependent arachidonic acid metabolites are essential modulators of the intestinal immune response to dietary antigen. Nat. Med. 5:900-906.

46. Morteau, O. 1999. COX-2: promoting tolerance. Nat. Med. 5:867-868.

47. Mashimo, H., Wu, D.C., Podolsky, D.K., and Fishman, M.C. 1996 Impaired defense of intestinal mucosa in mice lacking intestinal trefoil factor. Science. 274:262-265.

48. Kirtikara, K., et al. 1998. Compensatory prostaglandin E2 biosynthesis in cyclooxygenase 1 or 2 null cells. J. Exp. Med. 187:517-523.

49. Gilroy, D.W., et al. 1999. Inducible cyclooxygenase may have anti-inflammatory properties. Nat. Med. 5:698-701. 